\title{
Toward sustainability: Development of the Ningxia wine industry
}

\author{
Linhai Hao, Xueming Li, and Kailong Cao \\ Bureau of Grape Industry Development, Ningxia Hui Autonomous Region, People's Republic of China
}

\begin{abstract}
Ningxia government's key responsibilities for the grape and wine sector are sustainable economic development and natural resource management. While emerging as an industry leader in China, Ningxia has experienced many challenges, the major ones are increasing labor costs and seasonal worker shortages, production cost control, and a market dominated by domestic giants and increased imports. Ningxia government made policies to encourage the development of boutique wineries, high quality wines and wine tourism. On natural resource protection, a strict annual irrigation quota has led to the quick adoption of drip irrigation. New vineyards have been designed with a focus on mechanization. Fertilization program will be fine-tuned using the analysis of the soil and the mineral elements in leaves. Various personnel training programs have been organized every year. In summary, the potential of Ningxia wine region has already been proven, and Ningxia government will continually provide its support for the sustainable grape and wine development of the region.
\end{abstract}

\section{Introduction}

Government support plays a key role in industry development in China. For the grape and wine sector, the Ningxia government's key responsibilities are sustainable economic development and natural resource management. Ningxia is a relatively new wine region in China. The wine grape growing started in 1982 [1], mainly as grape base of Chinese big brands, namely Greatwall, Changyu and Dynasty, a few wineries were established to ferment the grapes, and the produced bulk wines were transported to Shandong and Hebei provinces for blending and sold under the brands of the big wineries, most of the cases Ningxia as the wine production region was not indicated on the bottle labels [2]. The early development introduced wine grape varieties to Ningxia, provided the basic viticulture experience on wine grape growing, and the wineries accumulated the early experience on wine fermentation and wine as a commercial products.

With the development of Chinese economy, domestic wine production increased from about 2 million hl in 2000 to 7.83 million hl in 2014 (data from China Alcoholic Drinks Association). During this period the vineyard acreage increased from 300,000 ha to 570,000 ha (Data from China Agriculturists Association). Urbanization and increased cultivation of economic crops promoted the price increase on farming land; there is also a sharp increase on the labor cost, especially after 2008. All these economical and social factors determined the Chinese wine production moving from east coastal China to northwest China. Ningxia, a province which is formally called "Ningxia Hui Autonomous Region". Wine is selected as a key agriculture sector of Ningxia, this decision is based on 1) there is demand on Chinese wine; 2) wine grapes grow well along the east foothill of Helan Mountain in Ningxia, 3) wine grape can provide relatively higher economic value than other crops.

\section{Progress}

The acreage of wine grapes in Ningxia increased from 2.66 thousand ha in 2003 [2] to 6.7 thousand ha in 2005 [1], and reached 39.3 thousand ha in 2014. To increase the value of wine grape growing and manage the challenge from Chinese giants and costal wine brands which significantly increased bulk wine import for blending and bottling since 2000s, Ningxia decided to adopt the chateau wineries strategy for its industry development. That is to introduce more wine brands in the industry, make full use of the strong business success motivation of each winery and their advantage in specific markets. Heavy public investment on new large scale wineries was not considered, as Chinese domestic giants have controlled most of the domestic sells, they are strong in consumer brand awareness and control the traditional distribution channels, the second reason is that with more and more imported bottled wines in the market, large scale winery produced Chinese wines are usually regarded as cheap and inferior in quality.

Ningxia government's understanding on sustainable wine development is an overall package includes economic, social and environmental factors. With increased income and accumulated wine experience, Chinese consumers are looking for domestic wines with good quality, good story and more personal communications. Small scale boutique wineries in general could better meet these requirements. In a short time of 5 years, Jia Bei Lan, Silver Heights, Kannan, Chandon and several other brands have built their reputation both domestically and internationally. These wineries are also very active in wine tourism and eager to use wine exhibitions, winemaker dinners, open days and other promotion ways to closely communicate with the consumers. 
Socially, as Ningxia boutique wineries grow their own vineyards (using the dessert land on the foothills of Helan mountain, Ningxia government provides 70 years vineyard land use license to the wineries), the grape growing is not paid by quantity, but with a focus on quality, the hired farmers are also provided high payment, more training and a closer relationship with the winery. More involvement in wine including winery visit and wine tastings, the farmers get better understand on wine quality requirements, and it is easier for them to control the yield and follow the viticulturists. On the government level, very poor farmers in whole village scale were organized and immigrated from the southern high mountain area of the region to the foothills of Helan Mountain, the labors are trained as wine grape growers, the family living standard and income are significantly improved.

Environmentally, there are a few major concerns. One is that Ningxia is a province in the shortage of water; will the water resource support the 1 million mu (66.6 thousand ha) vineyard plan? The annual available water resource of Ningxia is about 4.15 billion cubic meter, includes 4.0 billion cubic meter Yellow River water allocated by Yellow River Conservancy Commission [3]. An annual irrigation quota of 3,000 tons of water per hectare for vineyards has led to the adoption of the more efficient system of drip irrigation. At the same time, as corn production uses 2-4 times more water than grapes, corn acreage is decreasing in the whole package of agriculture.

The other environmental concern is the sand and dust pollution during the winter and spring. China is of continental climate, strong wind is blowing from Siberia to southeast of China in winter and spring. Northwest of China is considered as an important resource of the sand and dust of the storm. In Ningxia like other northwest provinces of China, the grapevines need to be buried in the soil to be protected from the coldness and dryness. This agriculture practice could leave large area of uncovered and mobilized surface soil. To decrease the dust and sand risk, Ningxia makes full use of it natural conditions and agricultural technologies. Henlan Mountain is in north to south direction, the east foothill is in general well protected from the strong wind, which is also the reason for the survival and development of a narrow belt shape vineyards. Protection forest belts are established to separate the vineyards of each boutique winery and decrease the wind. To decrease the cost of burying the vines and the risk of dust, new grape varieties which do not need bury are under test in Ningxia, now more than 130 ha are planted.

Fertilizers and pesticides are two other major costs in vineyards. A recent statistic showed that China uses about $1 / 3$ of total chemical fertilizers of the world and only $1 / 3$ of the applied fertilizers are absorbed by the crops, which means increased cost of the production and pollution of the environment. Following the plan to decrease agri-chemical application in China in the next 5 years by Chinese Ministry of Agriculture, Ningxia is testing fertigation using small dosage of fertilizer and implied in a more efficient way. Tailored fertilization programs will be fine-tuned using soil and leaf analysis data. High efficient foliage spray is also under test, which is expected to largely decrease the soil application of fertilizers. Better plant protection protocols connected with real-time meteorology information help to improve the efficiency of pesticides application. The use of drones and other technology in vineyard management is under study.

Grape quality is the base of wine quality, and the continuous wine quality improvement is crucial for Ningxia to improve its reputation and competitiveness in the market. Some viticulture techniques are inefficient as the industry is relatively new and the best methods are still being determined in areas such as grape selection, canopy management and fertilization. Ningxia government has taken numerous steps to deal with these issues. Ningxia has also launched an "omics" study to better understand how "terroir", rootstocks and viticulture practices influence berry qualities. The results could allow for tailored grape projects in Ningxia's wine sub-regions.

To improve the winemaking skills, besides the regular training programs, 2015 will hold the second Ningxia international winemaker competition. The first Ningxia international winemaker competition recruited 10 winemakers, 7 of them finally arrived and made their red wines in 2012, they took care of their wines for two years, in the end of 2014 the results of the competition have been announced. The host wineries responded that the competition brought them a good learning and communication experience. In 2015 , the scale of the international winemaker competition will be enlarged. The Ningxia government organized delegation for winery managers and staffs to visit France, US, Australia and New Zealand representative wine regions, to improve their understanding on the advanced level of vineyard, winery and wine tourism management.

In wine promotion, small boutique wineries learn from the successful business of Grace Vineyard, Helan Qingxue and Silver Heights, and have established a draft protocol on wine promotion and sells, include participate international and domestic wine competitions, follow with public relationship activities with wine journals and wine writers, wine tourism, wine dinners with distributers and consumers, and promotion with social media, they gradually gain their reputation, adjust their price and wine style, and establish their consumer circle. And the government is supporting the growth of wine tourism. As estate wine is the backbone for tourism, there is a strong focus on establishing Ningxia wine as a quality brand and on monitoring consumer feedback. The first wine tourism chateau classification was announced in 2013 and there will be a reevaluation in the end of 2015.

\section{Challenges and main responsibilities}

With all the effort and achievements, Ningxia is still facing many challenges on its wine industry development. In the beginning of Ningxia wine business, a few relatively large scale wineries have been established, their production capacity is around 100,000-200,000 hl per year, Guangxia and Xixia King are the represents. These wineries are largely dependent on bulk wine business with Chinese famous brands [4]. They are facing the competition of international bulk wine suppliers, low margin of the products, difficulties to build and promote their brand, establish distribution channels, revise marketing strategy, brand positioning, etc. 
Labor cost, labor availability and labor quality will be a long term challenge for sustainability. With the development of Chinese economy, the requirements of vineyard labors to increase their income are natural and understandable. At the same time, young labors with higher education level in their groups are largely move to cities and do not like to work in the agriculture sector. The major labor force in the rural area is elders and females. At present one labor can take care of 0.67 to 1 ha of vineyards in Ningxia [5]. Improvement on work efficiency is the key bottleneck to increase the labor income and control the wine cost at the same time. Standardization is promoted in Ningxia. New vineyards have been designed with a focus on mechanization rather than manual labor when it comes to burying and uncovering vines. And standardized viticulture has been promoted since 2013. That includes the introduction of high quality grafted vines and simplified training systems. High quality standard vineyard establishment provided the adoption of mechanization, now machine takes about $90 \%$ of vine burying and $65 \%$ of pull out vine task after the winter in standardized vineyards in Ningxia, mechanization is also promoted in growing season pruning and spraying. From 2014, a vineyard and winery machine exhibition is held in Yinchuan every year; a forum on mechanization not only encourages machine usage in Ningxia wine region, but also attracted the visitors from other wine regions in China, which demonstrated that mechanization is the trend for Chinese wine production.

Food safety and authentic are the most concerned topics by Chinese consumers. With increased reputation and increased number of wineries in the region, there is increased risk on faked bottles, organic wine supervision, agri-chemical residual and addictive control, mis-leading information and so on. Ningxia government works closely with Chinese Association of Alcoholic Drinks, and will release a series of rules and regulations, at the same time a neutral lab for food safety and authentic test will be established. International statistic methods will be gradually adopted by Ningxia wine industry, one example is that the winery production will be calculated and reported as tons of crushing, other than tons of produced wine.

\section{Summary}

Ningxia has been an observer of OIV for more than four years. With the OIV platform, Ningxia is learning as a new wine region. We have got strong support from OIV leadership and made friends from wine countries and observers all over the world. Our mission is to build on these and other achievements while pursuing sustainable economic and environmental development. The potential of Ningxia's "terroir" and its talented winemakers has already been proven and we are dedicated to sustaining that momentum.

\section{References}

[1] G. Qi, Sino-Overseas Grapevine and Wine. 5: 42-46 (2006). (In Chinese)

[2] C. Qin, 2003. Manager Daily. Oct. 26 (2003) (In Chinese)

[3] J. Si, Water Res. Manag. 23: 31-33 (2013) (In Chinese)

[4] G. Du, J. Agri. Sci. 33(3): 50-54 (2012). (In Chinese)

[5] Y. Li, X. Li, G. Zhang, G. Wang, Sino-Overseas Grapevine and Wine. 3: 74-77 (2010). (In Chinese) 